\title{
Viral causes of Vitiligo: A New Perspective for Vitiligo Pathogenesis
}

\section{Dwivedi M1*, Laddha $\mathrm{NC}^{2}$ and Begum $\mathrm{R}^{3}$}

${ }^{1}$ C. G. Bhakta Institute of Biotechnology, Uka Tarsadia University, Tarsadi, Surat, Gujarat394350, India

2In vitro Specialty Lab Pvt. Ltd., 2nd Floor, PK House, Ashram Road, Ellise bridge, Ahmedabad, Gujarat- 380006, India

${ }^{3}$ Department of Biochemistry, Faculty of Science, The Maharaja Sayajirao University of Baroda, Vadodara, Gujarat 390002, India

*Corresponding author: Mitesh Dwivedi, C. G. Bhakta Institute of Biotechnology, Faculty of Science, Uka Tarsadia University, Maliba Campus, Gopal Vidyanagar, Bardoli-Mahuva Road, Tarsadi, Bardoli, District- Surat, Gujarat-394350, India, Tel: +91-2625-254122; Email: mitesh_dwivedi@yahoo.com; mitesh.dwivedi@utu.ac.in

\section{Abstract}

Vitiligo is an acquired skin depigmenting disorder due to loss of functional melanocytes in the epidermis. Several hypotheses have been proposed to explain its etiopathogenesis; however autoimmune pathomechanisms have been suggested to play an important role in the disease development. Previously, the viral causes of vitiligo have been suggested to be involved in vitiligo pathogenesis, however at present there are no such studies available to elucidate the role of viruses in inducing autoimmune mechanisms in vitiligo. The current article briefly summarizes all previous and currently available such studies involving viruses in vitiligo pathogenesis. The vitiligo being a complex autoimmune disorder and an important disease of research opens a new way to look at the virus based autoimmune mechanisms to cause vitiligo.

\section{Short Communication}

Vitiligo is an acquired, progressive, multifactorial, depigmenting disorder characterized by the appearance of circumscribed white macules in the skin due to chronic, progressive loss of functional melanocytes in the epidermis [1] (Figure 1). The selective destruction of melanocytes results in the development of depigmented patches. As such vitiligo is hardly a disease of medical significance but there is more of a social stigma attached to it because of cosmetic reasons. Although it might be viewed as minor disorder, these patches gradually increase in size and cause lot of psychological stress in the patient, self esteem and social interactions, particularly in patients with deeply pigmented skin [2]. The prevalence studies revealed that the worldwide prevalence of vitiligo ranges between 0.5 and $2 \%$ [3]. Based on a few dermatological outpatient records the prevalence of vitiligo in India is found to be $0.46 \%$ to $8.8 \%$ [4]. 


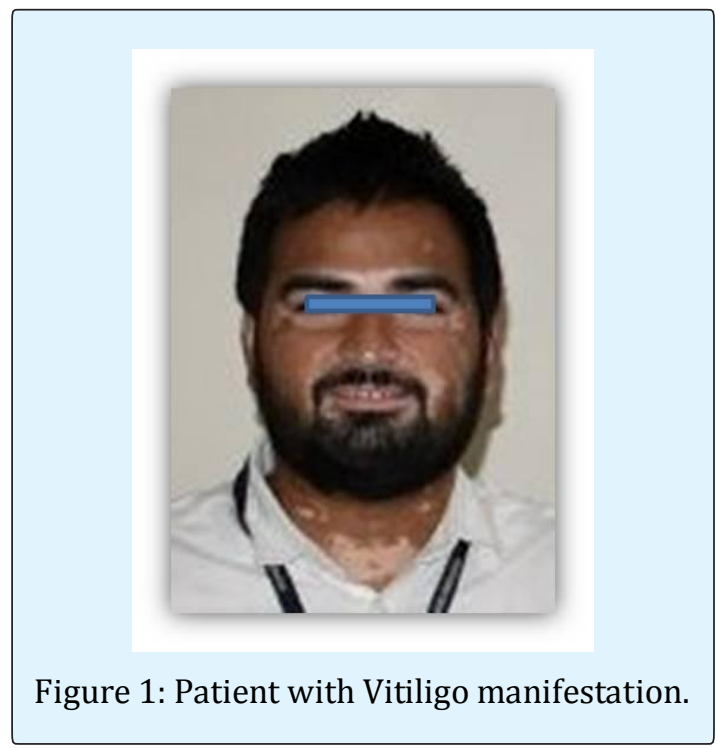

The exact aetiology and detailed pathogenesis of vitiligo is not fully understood, but autoimmunity has been strongly implicated in the development of the disease [5]. However, the involvement of microbial infections including the viruses cannot be avoided for vitiligo pathogenesis. The animal model studies showed that virus infection can trigger an autoimmune response. The viral peptide sequences may have molecular similarity with that of host cell antigens which in turn can activate the subsets of T-cells, resulting into autoimmunity. The virus may escape the detection after the onset of the disease $[6,7]$.

Since, chronic viral infections have been suggested to trigger the development of autoimmune diseases; vitiligo may be triggered by viral infection in a genetically predisposed host [8]. It has been suggested that virus induced T-cells could act against melanocytes. The virus can also attract leucocytes and macrophages leading in turn to the 'oxygen burst' via NADPH-oxidase concomitant with the production of ROS (such as superoxide radicals, H2O2), thus generating ROS pool in vitiligo. The association of vitiligo with such virus and/or viral diseases has been shown in Table 1 [8-24]. However, few studies deny the involvement of virus in vitiligo pathogenesis $[21,25]$.

Earlier studies have suggested that viruses may be involved in vitiligo pathogenesis. Viruses such as Cytomegalovirus (CMV) and Epstein Barr virus were detected in the epidermis of vitiligo patients [16,24]. The Herpes Zoster Virus was found in patients affected with segmental vitiligo [20]. The vitiligo was found to be associated with the Herpes Simplex Labialis Virus as well

\section{Virology \& Immunology Journal}

[22]. In addition, herpes virus connection was suggested in the expression of autoimmune vitiligo in Smyth line chickens [19]. Moreover, several studies have reported the association of vitiligo with HIV infection in AIDS patients either as a result of the infection itself or a complication of ART [8-15]. Tojo, et al. suggested that appearance of skin lesions in the early phase and their subsequent regression in the immunodeficient state indicate that certain immunological responses might be induced by HIV infection in the early course of this case [15]. Few studies have found that HIV infected persons led to development of psoriasis, alopecia universalis and alopecia areta suggesting that dermatological diseases including vitiligo may be due to autoimmunity caused by HIV virus in these patients $[8,9,13]$. However, one study has suggested that vitiligo was developed in AIDS patients after antiretroviral therapy [11].

The possible explanation for involvement of HIV in vitiligo development suggests that vitiligo could occur as a result of direct viral infection of melanocytes by HIV or by activated polyclonal B-cell directed against melanocytes surface receptor like melanin-concentrating hormone receptor 1 (MCHR1), and by excessive production of interferon- $\gamma$, or changes in the balance between helper and suppressor/regulatory $\mathrm{T}$ cells [10,26-29]. It has been observed that AIDS patients usually exhibit reduced numbers of $\mathrm{CD}^{+}$peripheral $\mathrm{T}$ cells and which might favour the development of vitiligo; since increased CD8 ${ }^{+}$ cells and decreased $\mathrm{CD}^{+}$cells have been observed in vitiligo patients [27]. Another study demonstrated that melanoma-derived Melan-A recognizing T-cell-lines were able to lyse T2 cells loaded with synthetic peptide sequences derived from viral origin; suggesting that $\mathrm{T}$ cells activated by virus could recognize self antigens and kill the host cells [30]. However, more research is needed to further understand the role of autoimmunity in AIDS.

Nevertheless, vitiligo has been found to be associated with chronic hepatitis $\mathrm{C}$ virus (HCV) infection and autoimmune hepatitis [17]. Akcan, et al. reported a low hepatitis B virus (HBV) sero-positivity in vitiliginous patients [18]. Moreover, it has been suggested that previous or concurrent cytomegalovirus (CMV) infections may induce the etiopathogenesis or deterioration of vitiligo [18,23]. In addition, the occurrence of cytomegalovirus DNA in skin biopsy specimens of vitiligo patients also suggested that viral infection could play a role in induction of vitiligo [24]. The involvement of other viruses such as Epstein-Barr virus, hepatitis E \& $C$ virus, herpes virus, herpes zoster virus, CMV, in addition to HIV is indicative of crucial role of viruses in development of vitiligo through modulating the immune system. 


\section{Virology \& Immunology Journal}

\begin{tabular}{|c|c|c|}
\hline $\begin{array}{c}\text { Virus } \\
\text { Infection/Disease }\end{array}$ & $\begin{array}{c}\text { Association with } \\
\text { Vitiligo }\end{array}$ & References \\
\hline HIV/AIDS & $\begin{array}{c}\text { Yes (along alopecia } \\
\text { areta) }\end{array}$ & [8] \\
\hline HIV/AIDS & $\begin{array}{l}\text { Yes (along with of } \\
\text { psoriasis, alopecia } \\
\text { universalis) }\end{array}$ & [9] \\
\hline HIV/AIDS & Yes & [10] \\
\hline HIV/AIDS & $\begin{array}{c}\text { Yes (after } \\
\text { antiretroviral } \\
\text { therapy) }\end{array}$ & [11] \\
\hline HIV/AIDS & Yes & [12] \\
\hline HIV/AIDS & $\begin{array}{l}\text { Yes (along with } \\
\text { alopecia areta) }\end{array}$ & [13] \\
\hline HIV/AIDS & Yes & {$[14]$} \\
\hline HIV/AIDS & Yes & [15] \\
\hline Epstein Barr Virus & Yes & [16] \\
\hline Hepatitis C virus & Yes & [17] \\
\hline Hepatitis B virus & Yes & [18] \\
\hline Herpes virus & $\begin{array}{l}\text { Yes (in Smyth line } \\
\text { chickens) }\end{array}$ & [19] \\
\hline $\begin{array}{l}\text { Herpes Zoster } \\
\text { Virus }\end{array}$ & $\begin{array}{c}\text { Yes (in Segmental } \\
\text { Vitiligo) }\end{array}$ & {$[20]$} \\
\hline $\begin{array}{l}\text { Herpes Simplex } \\
\text { virus }\end{array}$ & No (in Serum) & {$[21]$} \\
\hline $\begin{array}{l}\text { Herpes Simplex } \\
\text { Labialis Virus }\end{array}$ & $\begin{array}{c}\text { Yes (in Post- Herpes } \\
\text { Simplex Labialis } \\
\text { Vitiligo) }\end{array}$ & {$[22]$} \\
\hline Cytomegalovirus & Yes & {$[23]$} \\
\hline Cytomegalovirus & $\begin{array}{c}\text { Yes (in skin biopsy of } \\
\text { patients) }\end{array}$ & [24] \\
\hline
\end{tabular}

Table 1: Association of vitiligo with virus/viral diseases.

\section{Conclusion}

The previous studies involving the virus infection and vitiligo development propose a significant role of viral mechanisms for destruction of epidermal melanocytes which may serve as possible risk factor for vitiligo. The animal model studies will be helpful in delineating the virus based autoimmune mechanisms for vitiligo pathogenesis. However, currently there is a lacuna in such studies and hence it opens yet another line of investigation on finding out the crucial autoimmune mechanisms induced by viruses to elucidate and confirm the involvement of viruses not only in vitiligo pathogenesis but other autoimmune diseases as well.

\section{Acknowledgements}

We are thankful to Uka Tarsadia University, Bardoli, Gujarat, India for providing necessary facilities needed for the preparation of this article. We are thankful to Mr. Hardik Dwivedi for providing his photograph to explain the vitiligo manifestation.

\section{References}

1. Guerra L, Dellambra E, Brescia S, Raskovic D (2010) Vitiligo: pathogenetic hypotheses and targets for current therapies. Curr Drug Metab 11(5): 451-467.

2. Kent G, Al'Abadie M (1996) Psychologic effects of vitiligo: A critical incident analysis. J Am Acad Dermatol 35(6): 895-898.

3. Kruger C, Schallreuter KU (2012) A review of the worldwide prevalence of vitiligo in children/ adolescents and adults. Int J Dermatol 51(10): 12061212.

4. Shah H, Mehta A, Astik B (2008) Clinical and sociodemographic study of vitiligo. Indian J Dermatol Venereol Leprol 74(6): 701.

5. Le Poole IC, Luiten RM (2008) Autoimmune etiology of generalized vitiligo. Curr Dir Autoimmun 10: 227 243.

6. Von Herrath MG, Oldstone MB (1996) Virus induced autoimmune disease. Curr Opin Immunol 8(6): 878885.

7. Morse SS, Sakaguchi N, Sakaguchi S (1999) Virus and autoimmunity: induction of autoimmune disease in mice by mouse T-lymphotropic virus (MTLV) destroying CD4 and T cells. J Immunol 162(9): 53095316.

8. Gaurkar SP, Parmar KS, Shah BJ (2014) Letters to the Editor-Sequential development of psoriasis, alopecia universalis, and vitiligo vulgaris in a human immunodeficiency virus seropositive patient: A unique case report. Indian J Sex Trans Dis 35(2): 167169.

9. Xuan L, Baohua Y, Lan L (2014) Alopecia areata and vitiligo as primary presentations in a young male with human immunodeficiency virus. Indian J Dermatol 59(2): 209. 
10. Wang A (2012) Vitiligo in HIV/AIDS: a case report. J Am Acad Dermatol 66(4): AB181.

11. Defo D, Kouotou EA, Bissek AC, Mboua JB (2012) A case of vitiligo occurring after initiation of antiretroviral treatment and disappearing during this treatment: autoimmune IRIS syndrome? Ann Dermatol Venereol 139(11): 736-738.

12. Niamba P, Traoré A, Taïeb A (2007) Vitiligo in a black patient associated with HIV infection and repigmentation under antiretroviral therapy. Ann Dermatol Venereol 134(3 Pt 1): 272-273.

13. Cho M, Cohen PR, Duvic M (1995) Vitiligo and alopecia areata in patients with human immunodeficiency virus infection. South Med J 88(4): 489-491.

14. García-Patos Briones V, Rodríguez Cano L, Capdevila Morell JA, Costells Rodellas A (1994) Vitiligo associated with the acquired immunodeficiency syndrome. Med Clin (Barc) 103(9): 358.

15. Tojo N, Yoshimura N, Yoshizawa M, Ichioka M, Chida M, et al. (1991) Vitiligo and chronic photosensitivity in human immunodeficiency virus infection. Jpn J Med 30(3): 255-259.

16. Grimes PE, Elkadi T, Sanders J (1999) Epstein-Barr virus infection in patients with vitiligo (abstr). J Invest Dermatol 112: 604.

17. Akbayir N, Gökdemir G, Mansur T, Sökmen M, Gündüz $S$, et al. (2004) Is there any relationship between hepatitis C virus and vitiligo? J Clin Gastroenterol 38(9): 815-817.

18. Akcan Y, Kavak A, Sertbas Y, Olut AI, Korkut E, et al. (2006) The low seropositivity of hepatitis B virus in vitiligo patients. J Eur Acad Dermatol Venereol 20(1): 110-111.

19. Erf GF, Bersi TK, Wang X, Sreekumar GP, Smyth JR Jr (2001) Herpes virus connection in the expression of autoimmune vitiligo in Smyth line chickens. Pigment Cell Res 14(1): 40-46.

20. Gambhir ML, Pandey K, Kaur T (2014) Herpes zoster on segmental vitiligo: Wolf's isotopic response? Our Dermatol Online 5(2): 155-156.

\section{Virology \& Immunology Journal}

21. Liu Z, Qi R-Q, Zhao L-S, Sun X-D, Dong D-Y, et al. (2014) No Evidence of HSV Presence in the Serum of Vitiligo Patients. Pigmentary Disorders 1: 105.

22. Elethawi AMD (2013) Herpes Simplex Labialis Virus is A Risk Factor for Vitiligo (Post- Herpes Simplex Labialis Vitiligo). The Iraqi Postgraduate Medical Journal 12(3): 401-403.

23. Toker SC, Sarycaoglu H, Karadogan SK, Mistik R, Baskan EB, et al. (2007) Is there any relation between vitiligo and cytomegalovirus? J Eur Acad Dermatol Venereol 21(1): 141-142.

24. Grimes PE, Sevall JS, Vojdani A (1996) Cytomegalovirus DNA identified in skin biopsy specimens of patients with vitiligo. J Am Acad Dermatol 35(1): 21-26.

25. Würfel F, Panske A, Schallreuter KU (2000) Are viral infections a possible cause for the manifestation of vitiligo? Pigment Cell Res 13: 404.

26. Kemp EH, Waterman EA, Hawes BE, O'Neill K, Gottumukkala RV, et al. (2002) The melaninconcentrating hormone receptor 1 , a novel target of autoantibody responses in vitiligo. J Clin Invest 109(7): 923-930.

27. Dwivedi M, Laddha NC, Arora P, Marfatia YS, Begum R (2013) Decreased regulatory T-Cells and CD4+/CD8+ ratio correlate with disease onset and progression in patients with generalized vitiligo. Pigment Cell Melanoma Res 26(4): 586-591.

28. Dwivedi M, Kemp EH, Laddha NC, Mansuri MS, Weetman AP, et al. (2015) Regulatory $\mathrm{T}$ cells in vitiligo: Implications for pathogenesis and therapeutics. Autoimmunity Rev 14(1): 49-56.

29. Duvic M, Rapini R, Hoots WK, Mansell PW (1987) Human immunodeficiency virus-associated vitiligo: expression of autoimmunity with immunodeficiency? J Am Acad Dermatol 17(4): 656-662.

30. Loftus DJ, Castelli C, Clay TM, Squarcina P, Marincola FM, et al. (1996) Identification of epitope mimics recognized by CTL reactive to the melanoma/melanocyte derived peptide MART-1(2735). J Exp Med 184(2): 647-657. 